\title{
Sistemas de informações contábeis: proposição de um modelo de avaliação dos fatores críticos de sucesso*
}

\author{
Sistemas de informaciones contables: proposición de un modelo de evaluación de los factores \\ críticos de éxito \\ Accounting information systems: Proposal of an evaluation model of critical success factors
}

\author{
Ricardo Adriano Antonelli ${ }^{\text {a }}$ \\ Universidade Tecnológica Federal do Paraná, Brasil \\ rantonelli@utfpr.edu.br \\ ORCID: https://orcid.org/0000-0001-7606-2388 \\ Simone Bernardes Voese \\ Universidade Federal do Paraná, Brasil \\ ORCID: https://orcid.org/0000-0002-5555-8250 \\ Gilson Ditzel Santos \\ Universidade Tecnológica Federal do Paraná, Brasil \\ ORCID: https://orcid.org/0000-0002-7839-2281 \\ Marivânia Rufatto da Silva \\ Universidade Federal do Paraná, Brasil \\ ORCID: https://orcid.org/0000-0002-2098-1980
}

DOI: https://doi.org/10.11144/Javeriana.cc22.sicp

Recepção: 06/05/2020

Aprovação: 13/12/2020

Publicação: 18/08/2021

\section{Resumo:}

Esta pesquisa propõe um modelo composto por dez fatores críticos oriundos da literatura, e uma seleção de variáveis para avaliar o sucesso dos Sistemas de Informações Contábeis (SIC) nas Empresas Prestadoras de Serviços Contábeis (EPSC) do Brasil. A seleção das variáveis foi realizada seguindo o método Delphi em duas rodadas com 30 especialistas em SIC, contemplando empresas desenvolvedoras e usuários de SIC. Na primeira rodada, os especialistas sugeriram 75 variáveis críticas de sucesso e insucesso. Na segunda rodada, a partir das variáveis indicadas pela literatura e pelos especialistas (161), requisitou-se aos especialistas indicar as mais importantes, resultando em 74 variáveis distribuídas nos dez fatores que compõem o modelo teórico proposto. Destas, 41,9\% não são originadas da literatura.

Códigos JEL: M15, M41.

Palavras-chave: Sistemas de informações contábeis, fatores críticos de sucesso, insucesso, empresas prestadoras de serviços contábeis.

\section{Resumen:}

Esta investigación propone un modelo compuesto por diez factores críticos oriundos de la literatura, y una selección de variables para evaluar el éxito de los Sistemas de Informaciones Contables (SIC) en las Empresas Prestadoras de Servicios Contables (EPSC) del Brasil. La selección de las variables se realizó siguiendo el Método Delphi en dos rondas con 30 especialistas en SIC, contemplando empresas desarrolladoras y usuarios de SIC. En la primera ronda, los expertos sugirieron 75 variables críticas de éxito y fracaso. En la segunda ronda, a partir de las variables indicadas por la literatura y por los expertos (161), se solicitó a los expertos indicar las más importantes, resultando en 74 variables distribuidas en los diez factores que componen el modelo teórico propuesto. De estas, el 41,9\% no se originan de la literatura.

Códigos JEL: M15, M41.

Palabras clave: Sistemas de Informaciones contables, factores críticos de éxito, fracaso, empresas prestadoras de servicios contables.

\section{Autor notes}

\footnotetext{
a Autor de correspondência. E-mail: rantonelli@utfpr.edu.br
} 


\begin{abstract}
:
This research proposes a model composed of ten critical factors from the literature and a selection of variables. The purpose is to evaluate the success of the Accounting Information Systems (AIS) in Accounting Services Providers (ASP) from Brazil. The variables were selected by the Delphi Method in two rounds with 30 experts in AIS, including developer companies and ASP users. In the first round, the experts suggested 75 critical success and failure variables. In the second round, the specialists were asked to choose from the variables indicated by the literature and the specialists (161), those that they consider the most important. Results in 74 variables are distributed in the ten factors that compose the proposed theoretical model. From these, $41.9 \%$ of variables are not originated from the literature.
\end{abstract}

JEL Codes: M15, M41.

Keywords: Accounting information systems, critical success factors, failure, accounting services providers.

\title{
Introdução
}

No Brasil, de acordo com o Conselho Federal de Contabilidade (CFC), em novembro de 2017 existiam 62.701 Empresas Prestadoras de Serviços Contábeis (EPSC) (CFC, 2017), configurando-se como as principais responsáveis pela rotina contábil-tributária das organizações brasileiras (SESCON-SP, 2014).

A partir do ano de 2007, a realidade das EPSC foi fortemente alterada devido à implantação por parte do Governo Brasileiro de novas ferramentas de Governo Eletrônico para as empresas, o conhecido Sistema Público de Escrituração Digital (SPED). Com isso, os Sistemas de Informações Contábeis (SIC) começaram a ter que gerar informações ao Governo de forma periódica e padronizada. Os SIC devem ser entendidos como a intersecção dos domínios das áreas da Contabilidade e da Ciência da Computação (Gray, Chiu, Liu $\& \mathrm{Li}, 2014$ ), além de serem o meio utilizado pelos profissionais contábeis para gerar informações confiáveis aos diversos stakeholders (Etim, 2011). Essa inovação tecnológica vivida pelas EPSC nos últimos anos permitiu maior agilidade na prestação dos serviços e melhorias na qualidade da informação. Contudo, junto com as inovações, isto gerou uma maior complexidade na realização das tarefas para as organizações (Zwirtes \& Alves, 2014).

Nesse contexto, o fornecimento de informações relevantes para a tomada de decisão é um ponto importante para o sucesso dos SIC (Coelho \& Souza, 2005), mas existem indícios que tais sistemas não atendem completamente essa necessidade (Souza \& Passolongo, 2005; Lopes, 2011).

Neste sentido, muitos pesquisadores passaram a investigar os fatores de sucesso ou insucesso dos Sistemas de Informação (SI). Enquanto algumas pesquisas empíricas, a exemplo de Dwivedi, Wastell, Laumer et al. (2015) e Nelson $(2005,2007)$, têm buscado por meio dos fatores de insucesso, compreender as elevadas falhas na utilização de algumas tecnologias, outros estudos avaliam quais seriam os fatores críticos que poderiam contribuir para o uso eficiente da tecnologia, para que a mesma retorne os benefícios esperados.

DeLone e McLean (1992) propuseram um modelo para avaliar o sucesso de um SI cuja utilização ainda é ampla. O referido modelo, posteriormente aprimorado por DeLone e McLean (2003), define que o sucesso de um SI é o resultado dos seguintes fatores/dimensões: qualidade do sistema, qualidade da informação, qualidade de serviço, uso, intenção de uso, satisfação do utilizador e benefícios líquidos. Adicionalmente, de acordo com o modelo de DeLone e McLean (1992, 2003), é possível veriificar na literatura vários estudos que indicam uma combinação de variáveis a serem utilizadas em cada dimensão [ou fator] para medir o sucesso de um sistema de informação. Tal é o caso de Al-Debei, Jalal e Al-Lozi (2013), Esteves (2007), Freitas (2013), Machado e Oliveira (2006), Moura (1997), Sanchez, Cruz e Agapito (2012), Santos, Beltrame e Lunardi (2007), Wu e Wang (2006), entre outros.

Além desses, outros autores também propuseram diferentes modelos para avaliar o sucesso de sistemas de informação, destacando-se: Davis (1986), Davis, Bagazzi e Warshaw (1989), Goodhue e Thompson (1995), Seddon (1997), Rosemman Michael e Wiese (1999), Markus e Tanis (2000), Stefanou (2001), Smyth (2001), Gable, Sedera e Chan (2003), Wixom e Todd (2005), Ifinedo (2006), Sabherwal, Jeyaraj e Chowa (2006) entre outros. Já no contexto específico da contabilidade, são poucas as pesquisas que 
buscaram avaliar o sucesso dos SIC, como Seddon e Kiew (1996), Floropoulos, Spathis, Halvatzis e Tsipouridou (2010), Fitriati e Mulyani (2015) e Mulyani, Hassan e Anugrah (2016), e ainda assim utilizaram modelos parciais, que não investigam o sucesso de forma abrangente.

Deve-se ressaltar que a definição de sucesso tem sido um desafio (Petter, DeLone \& McLean, 2013), visto que, por sua natureza multidimensional e interdependente (DeLone \& McLean, 2003), sua mensuração requer a definição e medição de um conjunto de fatores combinados e inter-relacionados (DeLone \& McLean, 1992). Nesses termos, nos estudos citados, o sucesso é tratado como um constructo dependente, que é resultado de um conjunto de fatores independentes, chamados, nesta pesquisa, de fatores críticos [ou dimensões], que por meio de um conjunto de variáveis representam uma perspectiva de avaliação do SI. Todavia, observou-se que não existe unanimidade entre os estudos analisados sobre o conjunto de variáveis que melhor representam cada fator crítico, em um modelo de avaliação de sucesso de SI.

Este estudo, ciente da importância de entender melhor o sucesso dos SIC para os professionais contábeis e para as EPSC, investiga a seguinte questão: Quais os fatores críticos e suas respectivas variáveis que podem compor um modelo de avaliação do sucesso dos Sistemas de Informações Contábeis nas Empresas Prestadoras de Serviços Contábeis? Para tal efeito, busca-se propor um modelo composto de fatores críticos com suas respectivas variáveis para avaliar o sucesso dos Sistemas de Informações Contábeis nas Empresas Prestadoras de Serviços Contábeis.

A proposição de um modelo que avalie o êxito dos SIC utilizados pelas EPSC justifica-se pelas razões adjacentes. $\mathrm{O}$ estudo se centra nas EPSC devido a sua comprovada representatividade na economia brasileira, sendo que atingiram uma receita líquida operacional de R \$238 bilhões em 2011, representando 6,47\%do Produto Interno Bruto (PIB), de acordo com dado divulgado pelo Instituto Brasileiro de Geografia e Estatística (IBGE) (Capozoli, 2014; IBGE, 2014). Dessa forma, o conhecimento dos fatores críticos do sucesso dos SIC pode auxiliar as EPSC na melhoria da performance interna, de forma operacional, tática e estratégica.

Adicionalmente, é importante o conhecimento dos fatores críticos para avaliação do sucesso dos SIC, pois existe uma forte relação entre o sucesso dos SIC e a qualidade das informações contábeis (Fitriati e Mulyani, 2015), juntamente com a falta de um modelo específico para avaliar o êxito dos SIC nas EPSC, no ambiente brasileiro. Entender melhor como ocorre o sucesso de tais sistemas poderá contribuir a uma melhor qualidade da informação contábil, nos aspectos de relevância, precisão, tempestividade e integralidade (Susanto, 2015).

Ainda, na análise da literatura, verifica-se que mais de 14 estudos buscaram adaptar/ajustar o modelo de sucesso de DeLone e McLean (1992, 2003) para 11 tipos de sistemas, dos quais nenhum é SIC (Sanchez et al., 2012). Portanto, esta pesquisa contribui na literatura por propor um rol de fatores e variáveis abrangentes para medição do sucesso dos SIC nas EPSC, os quais não se limitam aos sugeridos por DeLone e McLean (1992, 2003). Igualmente, este estudo se consideram não apenas fatores críticos de sucesso dos SIC, mas também os de insucesso, o que é muito escasso na literatura vigente.

\section{Proposta de um modelo de avaliação de sic}

Para formar uma base teórica de pesquisas precedentes de modelos de avaliação do êxito dos SIC, foram achados os seguintes modelos na literatura existente: Seddon e Kiew (1996), Floropoulos et al. (2010), Fitriati e Mulyani (2015) e Mulyani et al. (2016). Diante dos poucos estudos relacionados às SIC, buscou-se na literatura modelos de sistemas de informações variados, dos quais selecionaram-se os estudos indicados a seguir.

O ponto de partida para a proposição do modelo desta pesquisa é o modelo IS Success, atualizado de DeLone e McLean (1992, 2003). Tal modelo é amplamente utilizado pelos pesquisadores, possuindo mais de 2.900 citações na base de dados $\operatorname{Scopus}^{\circledR}$ (consulta realizada no ano de 2016). Adicionalmente, 
Correa, Peréz e Flores (2016) trabalharam em uma meta-análise com 83 estudos publicados entre 1992 e 2014 e que replicaram o modelo IS Success. Os autores analisaram 14 relações entre os fatores do modelo de DeLone e McLean $(1992,2003)$ e concluíram que a maioria delas são fortes ou moderadas, indicando a robustez do modelo.

Diante da escolha do modelo inicial IS Success, seus fatores críticos considerados são: (i) Qualidade da Informação; (ii) Qualidade do Sistema; (iii) Qualidade do Serviço; (iv) Intenção de Uso; (v) Uso; (vi) Satisfação do Usuário; e (vii) Benefícios Líquidos, subdivididos em individuais e organizacionais. O primeiro procedimento foi a retirada do fator Intenção de Uso, pois os SIC são sistemas de uso obrigatório, além de que as EPSC no ambiente vigente no Brasil só conseguem desempenhar suas atividades servindo-se do SIC.

Cabe destacar que os SIC utilizados pelas EPSC brasileiras se caracterizam como um sistema que processa dados recebidos de outros sistemas, em especial dos ERP (Enterprise Resource Planning), e que, após o processamento dos dados, estes são apresentados na forma de informação contábil. Deste modo, o fator Qualidade da Informação do modelo proposto originalmente por DeLone e McLean (2003) foi ajustado para Qualidade dos Dados Recebidos, termo sugerido por esta pesquisa. Além disso, Fitriati e Mulyani (2015) afirmam que os fatores de sucesso dos SIC implicam na Qualidade da Informação Contábil, assim, adicionou-se a variável Qualidade da Informação Contábil [gerada] ao fator - Benefícios Líquidos.

$\mathrm{Na}$ análise dos estudos específicos em SIC, Fitriati e Mulyani (2015) detectaram que as variáveis Comprometimento e Cultura Organizacional representadas pelo fator Aspectos Organizacionais afetam significtivamente o sucesso dos SIC, o que motivou a inserção de tal constructo nesta pesquisa, relacionado ao fator Benefícios Líquidos.

$\mathrm{Na}$ sequência, dado que os SIC utilizados pelas EPSC brasileiras devem atender a várias tarefas regulamentadas pelo Governo Brasileiro, acrescentou-se no modelo o fator Características da Tarefa do modelo TTF (Task-Technology Fit) de Goodhue e Ao mpson (1995) e Smyth (2001). A inclusão da dimensão Características da Tarefa levou em consideração o estudo de Sun e Teng (2012) para avaliar o sucesso dos sistemas de informações, e dar uma melhor contextualização das atividades e dos subsistemas [ou módulos] utilizados pelos usuários. Dessa forma, o fator Características da Tarefa juntamente às dimensões já existentes no modelo proposto, representam a decomposição do ajuste da tarefa nos oito componentes previstos por Goodhue e Thompson (1995), que são: (i) qualidade dos dados, (ii) disponibilidade e localização dos dados, (iii) autorização para acesso aos dados, (iv) compatibilidade dos dados, (v) facilidade de uso/treinamento, (vi) cumprimento de prazos, (vii) confiabilidade dos sistemas e (viii) relacionamento com os usuários.

Mulyani et al. (2016) encontrou relações estatisticamente significativasdo Uso dos SIC com Aspectos Sociais. No mesmo sentido, DeLone e McLean (2003) confirma que os aspectos sociais têm fortes indícios de influência na utilização do sistema. Diante de tais acepções, Mulyani et al. (2016) incluíram a dimensão Aspectos Sociais dos usuários do sistema, composta pelas variáveis: (i) Auto Eficácia, (ii) Atitudes Pessoais e (iii) Normas Subjetivas.

Por último, considerando que muitos sistemas não têm o sucesso esperado devido a fatores de insucesso, no modelo proposto é incluída a dimensão Fatores de Insucesso que influenciam negativamente na dimensão Benefícios Líquidos. Neste aspecto seguem-se as considerações de Nelson (2007) e de Fowler e Horan (2008), que indicam a importância de as pesquisas analisarem não apenas a tecnologia como fator de sucesso, mas também os fracassos de sua implementação.

A partir do levantamento teórico descrito, foi possível identificar um conjunto de dez fatores críticos de sucesso, definidos conforme a tabela 1 . 
TABELA 1

Descrição dos fatores críticos de sucesso

\begin{tabular}{|c|c|}
\hline Fatores críticos & Descrição \\
\hline $\begin{array}{l}\text { Qualidade dos dados } \\
\text { recebidos }\end{array}$ & $\begin{array}{l}\text { Compreende a avaliação do dado recebido pelo sistema, muitas } \\
\text { vezes, oriundo de sistemas empresariais. }\end{array}$ \\
\hline Qualidade do sistema & $\begin{array}{l}\text { Busca avaliar se as características do SIC satisfazem as } \\
\text { características desejadas pelos seus usuários. }\end{array}$ \\
\hline Qualidade do serviço & $\begin{array}{l}\text { Representa o apoio global emitido pelo fornecedor do software SIC } \\
\text { (desenvolvedora de SIC) aos usuários do sistema e a empresa } \\
\text { utilizadora do sistema. }\end{array}$ \\
\hline $\begin{array}{l}\text { Características da } \\
\text { tarefa }\end{array}$ & $\begin{array}{l}\text { Busca avaliar as tarefas (ou rotinas) que são executadas pelos } \\
\text { usuários do SIC a fim de transformar os insumos (entrada) em } \\
\text { resultados (saída). }\end{array}$ \\
\hline Aspectos sociais & $\begin{array}{l}\text { Busca avaliar a confiança que o usuário possui para realizar com } \\
\text { sucesso as tarefas do sistema, as atitudes pessoais do usuário com } \\
\text { relação ao sistema, e ainda, como o ambiente organizacional } \\
\text { influência na avaliação individual do usuário do sistema em uso. }\end{array}$ \\
\hline Uso & Busca avaliar o montante de uso efetivo do sistema pelo usuário. \\
\hline Satisfação do usuário & Avalia o nível de satisfação do usuário com o sistema. \\
\hline $\begin{array}{l}\text { Aspectos } \\
\text { organizacionais }\end{array}$ & $\begin{array}{l}\text { Visa avaliar o grau em que o funcionário se identifica com a } \\
\text { empresa em que trabalha, aceitando e acreditando nas metas } \\
\text { organizacionais, além do desejo de permanecer na organização e o } \\
\text { conjunto de hábitos e crenças compartilhados por seus membros. }\end{array}$ \\
\hline Fatores de insucesso & $\begin{array}{l}\text { Busca avaliar as eventuais falhas desde a implantação até o uso } \\
\text { efetivo do sistema na organização. }\end{array}$ \\
\hline Benefícios líquidos & $\begin{array}{l}\text { Busca medir os benefícios tanto a nível individual dos usuários do } \\
\text { SIC, como os benefícios organizacionais da empresa que o utiliza. }\end{array}$ \\
\hline
\end{tabular}

Fonte: os autores.

A estes fatores foi adicionado o fator simbólico "Adequação Tecnologia-Tarefa” (TTF), sem variáveis representativas, pois estas já estão representadas nos fatores "Qualidade dos Dados Recebidos", "Qualidade do Sistema", "Características da Tarefa" e "Qualidade do Serviço".

Além disso, considerando as diferentes fases no processo de implantação e utilização dos sistemas de informações estudados por Markus e Tanis (2000), adicionou-se ao modelo proposto a variável de controle "Fase do Projeto". Isto devido a que os benefícios líquidos obtidos pelo uso do sistema de informação podem diferir entre as fases do processo de implantação e utilização (Stefanou, 2001).

Considerando os estudos até aqui relacionados, detectou-se na literatura inicialmente uma lista de 220 variáveis. A fim de redução deste número, selecionou-se apenas as variáveis que foram utilizadas especificamente em estudos de SIC (Seddon \& Kiew, 1996; Floropoulos et al., 2010; Fitriati \& Mulyani, 2015; Mulyani et al., 2016); ou demonstraram forte relação em estudos anteriores verificados por Petter et al. (2013), culminando em 99 variáveis.

\section{Metodologia}

A pesquisa possui caráter descritivo com objetivo formal, que para coleta de dados serve-se do método de interrogação/comunicação (Cooper \& Schindler, 2003). A fim de viabilizar a avaliação dos SIC, diante do grande número de variáveis sugeridas na literatura, optou-se pela utilização do método Delphi que permite a sua redução.

A escolha do método Delphi deu-se por ser uma técnica interativa e de previsão qualitativa, na qual especialistas opinam anonimamente por meio de rodadas de questionários sobre determinado tema no qual possuem conhecimento (Bugarim, 2012). De tal modo, é possível obter consenso sobre as variáveis mais importantes para representar os fatores críticos do modelo proposto na pesquisa. Para escolha dos especialistas considerou-se a importância de uma distribuição equilibrada entre elementos, sendo que a heterogeneidade dos especialistas é um fator estimulante aos participantes (Wright \& Giovinazzo, 2000). Com isso, buscou-se a opinião dos especialistas envolvidos com os SIC desde sua concepção até sua efetiva utilização. Os grupos de especialistas que deveriam participar do método Delphi foram escolhidos por um critério de acessibilidade. Foram selecionadas cinco EPSC do sudoeste do Estado do Paraná e onze 
empresas desenvolvedoras de SIC do Brasil. Com relação às EPSC, estas foram visitadas pessoalmente e todas aceitaram participar da pesquisa. Já a respeito das empresas desenvolvedoras de SIC, as onze empresas foram contatadas via telefone em julho de 2017. Neste caso, foi feita uma breve apresentação do estudo, e posteriormente, encaminhou-se o convite de participação por e-mail, garantindo seu anonimato caso aderissem à pesquisa. Como resultado, obteve-se o aceite de participação de três empresas localizadas na região Sul do Brasil.

Visando determinar os grupos de especialistas que participariam da pesquisa, as três empresas desenvolvedoras e as cinco EPSC foram questionadas sobre suas respectivas estruturas de profissionais de SIC. Nas EPSC foram selecionados dois grupos de usuários dos SIC que são típicos dessa realidade: (i) gestores das EPSC que detêm uma visão mais tática e estratégica dos SIC; e (ii) usuários dos SIC que representam uma visão mais operacional do sistema. Já nas empresas desenvolvedoras de SIC, embora existam diferentes nomes de cargos, é possível identificar quatro grupos de especialistas envolvidos com os SIC: (i) gestores, responsáveis por toda gestão do SIC, desde sua concepção até seu suporte ao cliente; (ii) coordenadores de análise e desenvolvimento, responsáveis pela análise e programação do software; (iii) responsáveis de suporte ao cliente, com contato direto com os usuários do SIC para suprir suas dúvidas e necessidades; e (iv) consultores e implantadores, envolvidos com a venda e implantação do SIC.

Adicionalmente, na análise do site das onze empresas desenvolvedoras de SIC do Brasil, as mesmas que foram convidadas para participarem da pesquisa como especialistas, constatou-se que tais sistemas são subdivididos em cinco módulos, sendo quatro operacionais: Contabilidade, Fiscal, Folha de Pagamento (RH) e Controle Patrimonial; e um módulo de gerenciamento, aqui denominado Gestor de Escritório Contábil. Diante disso, observou-se que os especialistas nem sempre têm conhecimento em todos os módulos do SIC, sendo necessário verificar dentro de cada grupo em qual(is) módulo(s) havia experiência profissional.

Com relação ao número de especialistas no método Delphi, Grisham (2009) indica que na literatura existem estudos com mais de 60 especialistas e outros com menos de 15. Para Giovinazzo (2001), um número de 15 a 30 especialistas é suficiente para gerar informações relevantes. Nestes termos, quanto aos especialistas do grupo pertencente às EPSC, foram convidados 16 funcionários e três gestores de EPSC da região sudoeste do Paraná das cinco EPSC anteriormente selecionadas, devido a acessibilidade dos mesmos, todos formados em nível superior em Ciências Contábeis. Já nas empresas desenvolvedoras de SIC, as três participantes da pesquisa indicaram dentro de seus colaboradores, aqueles que iriam participar. No total, foram obtidas as confirmações de participação de 39 especialistas de SIC, conforme dispostos na Tabela 2.

TABELA 2

Relação dos especialistas confirmados na participação da pesquisa

\begin{tabular}{|c|c|c|c|c|c|c|c|}
\hline \multirow{2}{*}{ Grupo } & \multirow{2}{*}{ Subgrupo } & \multicolumn{5}{|c|}{$\begin{array}{l}\text { Especialistas com experiência } \\
\text { nos módulos: }\end{array}$} & \multirow{2}{*}{$\begin{array}{l}\text { Número de } \\
\text { participantes }\end{array}$} \\
\hline & & MC & MF & MP & RH & MG & \\
\hline \multirow{2}{*}{ EPSC } & Gestores & 04 & 04 & 04 & 04 & 01 & 04 \\
\hline & Usuários & 09 & 09 & 09 & 09 & 00 & 17 \\
\hline \multirow{5}{*}{$\begin{array}{l}\text { Empresas } \\
\text { desenvolvedoras } \\
\text { de SIC }\end{array}$} & Gestores & 03 & 03 & 03 & 03 & 02 & 04 \\
\hline & $\begin{array}{l}\text { Coordenadores de análise } \\
\text { e desenvolvimento }\end{array}$ & 04 & 04 & 04 & 03 & 02 & 06 \\
\hline & $\begin{array}{l}\text { Responsáveis de suporte } \\
\text { ao cliente }\end{array}$ & 02 & 02 & 02 & 02 & 01 & 04 \\
\hline & $\begin{array}{l}\text { Consultores e } \\
\text { implantadores }\end{array}$ & 04 & 04 & 04 & 04 & 04 & 04 \\
\hline & Total Geral & 26 & 26 & 26 & 25 & 10 & 39 \\
\hline
\end{tabular}

Legenda: MC = Módulo Contábil; MF = Módulo Fiscal; MP = Módulo Patrimônio; RH = Módulo Folha de Pagamento; MG = Módulo Gestor de Escritório Contábil.

Fonte: dos autores.

$\mathrm{Na}$ análise da tabela 2, pode-se observar que foram selecionados participantes que possuem experiência em pelo menos um módulo do SIC, e todos os módulos do SIC possuem especialistas com experiência em todos os subgrupos. Isto contribui com a qualidade dos resultados a serem coletados, conforme indicado por Wright e Giovinazzo (2000).

Para a coleta de dados, duas amostras foram selecionadas. A primeira amostra foi utilizada pelas duas rodadas do Método Delphi, com 39 especialistas selecionados. Na primeira rodada, foram recebidas 30 
respostas válidas, representando uma taxa de participação de 76,9\%. Já na segunda rodada, obteve-se um retorno de 28 respostas completas (72\%).

A segunda amostra teve o objetivo de validar o resultado obtido com os especialistas da primeira. Para isso, selecionou-se 15 usuários de SIC que trabalham em EPSC no Estado do Paraná, selecionados por acessibilidade, com os seguintes requisitos: (i) com formação em nível superior em Ciências Contábeis; (ii) mais de dois anos de experiência em SIC de EPSC. Assim, para tais usuários foi requisitado que avaliassem as variáveis propostas, indicando a necessidade de eventuais adequações. Foi obtido retorno de 12 usuários $(80 \%)$.

\section{Análise dos resultados}

Os resultados desta pesquisa são descritos em três tópicos, os dois primeiros referem-se às duas rodadas dos especialistas realizadas na operacionalização da técnica $D e l p h i$, e o último, referente à validação das variáveis mais expressivas selecionadas para representarem os fatores do modelo teórico proposto.

\section{Primeira Rodada Método Delphi}

Antes de indicar aos 39 especialistas as variáveis relacionadas pela literatura, nesta primeira rodada optou-se por requisitar para que cada um indicasse, de acordo com sua experiência profissional, quais os fatores críticos que podem contribuir para o sucesso ou insucesso dos SIC. Para tanto, utilizou-se um questionário de perguntas abertas de elaboração própria, no qual os respondentes deveriam indicar os fatores de sucesso e de insucesso que os mesmos entendem importantes. Com isso, esta primeira rodada não induz aos especialistas a selecionar fatores já existentes na literatura, mas busca avaliar quais fatores são citados por eles mesmos.

Considerando que os SIC pesquisados das onze empresas desenvolvedoras de SIC são subdivididos em módulos, nesta primeira rodada optou-se por separar os fatores críticos por módulos, para posteriormente avaliar se tais fatores são ou não análogos entre os módulos estudados. Estes módulos são: Módulo Contábil (MC), Módulo Fiscal (MF), Módulo Patrimônio (MP), Módulo Folha de Pagamento (RH) e Módulo Gestor de Escritório Contábil (MG). Caso houvesse outros eventuais módulos do SIC que não haviam sido relacionados na pesquisa, foi requisitado aos especialistas a sua indicação, bem como seus respectivos fatores críticos de sucesso ou insucesso. Sendo assim, o questionário desta primeira rodada foi composto por doze questões abertas, duas (uma de sucesso e outra de insucesso) para cada módulo relacionado, e por último, duas questóes para outros eventuais módulos sugeridos pelos respondentes.

Assim, com um total de 30 respostas válidas, estas foram analisadas e sintetizadas na tabela 3, relacionando os fatores críticos de sucesso de acordo com a opinião dos especialistas, indicando a frequência com que cada fator foi lembrado, e separados pelos módulos MC, MF, MP, RH e MG. Cabe citar que os respondentes não indicaram nenhum outro módulo do SIC, além dos cinco já relacionados pela pesquisa. 
TABELA 3

Fatores críticos de sucesso indicados pelos especialistas por módulo do SIC (Continua).

\begin{tabular}{|c|c|c|c|c|c|c|}
\hline \multicolumn{7}{|c|}{ FATORES DE SUCESSO (FS) } \\
\hline \multirow{2}{*}{ Cód. } & \multirow{2}{*}{ Descrição do fator } & \multicolumn{5}{|c|}{ Frequência de Ocorrência } \\
\hline & & MC & MF & MP & RH & MG \\
\hline 01 & $\begin{array}{l}\text { Personalização de relatórios e saídas (Planilha eletrônica) conforme } \\
\text { necessidade dos usuários }\end{array}$ & 11 & 5 & 01 & 05 & 01 \\
\hline 02 & $\begin{array}{l}\text { Integração com os outros módulos ou sistemas (módulos do SIC e } \\
\text { sistemas externos, como por exemplo, sistema de gestão das empresas) }\end{array}$ & 10 & 10 & 09 & 04 & \\
\hline 03 & Facilidade de uso e aprendizagem & 07 & 05 & 05 & 05 & 01 \\
\hline 04 & Interface amigável (simples) & 05 & 04 & 04 & 05 & 01 \\
\hline 05 & $\begin{array}{l}\text { Integração com sistemas do governo (SPED, FCONT, DIPJ, GIAS, } \\
\text { Sintegra, SEFIP, CAGED, E-SOCIAL, RAIS e etc.) }\end{array}$ & 04 & 09 & 03 & 07 & 01 \\
\hline 06 & Atender a legislação vigente, tanto a fiscal como a trabalhista & 04 & 08 & 03 & 07 & 01 \\
\hline 07 & Suporte técnico efíciente e acessível & 03 & 03 & 02 & 04 & 02 \\
\hline 08 & $\begin{array}{l}\text { Rotinas e tarefas automatizadas (alteração em massa de lançamentos, } \\
\text { encerramento exercícios, cálculos folha, apuração tributos, } \\
\text { depreciações, faturamento e conferências) }\end{array}$ & 02 & 02 & 02 & 04 & 02 \\
\hline 09 & Sistema prático (ou direto) & 02 & 01 & 01 & 01 & 01 \\
\hline 10 & Plano de contas dinâmico (ajustável) & 02 & & & & \\
\hline 11 & Equipe de desenvolvimento do software capacitada & 02 & 01 & 01 & & \\
\hline 12 & Auditoria dos dados ou informações & 02 & 03 & 02 & 01 & 01 \\
\hline 13 & Treinamento adequado dos usuários & 02 & 02 & 02 & 04 & \\
\hline 14 & $\begin{array}{l}\text { Comprometimento dos usuários e da empresa desenvolvedora de SIC } \\
\text { com a implantação do sistema }\end{array}$ & 02 & 02 & 02 & 01 & 01 \\
\hline 15 & Conhecimento contábil (legislação) dos usuários do software & 02 & 02 & 01 & 02 & 01 \\
\hline 16 & Sistema ágil & 02 & & & & 01 \\
\hline 17 & O software utiliza tecnologias consolidadas & 01 & 01 & 01 & & \\
\hline 18 & Sistema objetivo & 01 & 01 & 01 & 01 & \\
\hline 19 & Software livre de erros (bugs) & 01 & 01 & 01 & & \\
\hline 20 & Regras do negócio consolidadas & 01 & 01 & 01 & & \\
\hline 21 & Software flexível às necessidades dos usuários & 01 & 01 & 02 & 03 & 01 \\
\hline 22 & Controle de acesso aos usuários & 01 & 01 & 01 & 01 & 01 \\
\hline 23 & Software melhorado de forma contínua & 01 & 01 & 01 & & \\
\hline 24 & Sistema, relatórios e processos confiáveis & 01 & 01 & 01 & 01 & \\
\hline 25 & Qualidade da informação gerada pelo software & 01 & 02 & & 01 & \\
\hline 26 & Segurança dos dados e informações & 01 & 01 & 01 & & \\
\hline 27 & Equipe de implantação do software capacitada & 01 & 01 & 01 & 01 & 01 \\
\hline 28 & Agilidade na correção de erros (bugs) & 01 & 01 & 01 & & \\
\hline 29 & Baixo custo do software & 01 & 01 & 01 & 01 & 01 \\
\hline 30 & Implantação do software planejada & 01 & 01 & 01 & 01 & 01 \\
\hline 31 & Sistema atualizado & 01 & 04 & 01 & 03 & 01 \\
\hline 32 & Inovação tecnológica & 01 & 01 & 01 & 01 & 01 \\
\hline 33 & Software bem desenvolvido & 01 & 01 & 01 & & \\
\hline 34 & Opções de compra do software por módulos e/ou locação & 01 & 01 & 01 & 01 & 01 \\
\hline
\end{tabular}

Fonte: dos autores. 
TABELA 3

Fatores críticos de sucesso indicados pelos especialistas por módulo do SIC (Continua).

\begin{tabular}{|c|c|c|c|c|c|c|}
\hline \multicolumn{7}{|c|}{ FATORES DE SUCESSO (FS) } \\
\hline \multirow{2}{*}{ Cód. } & \multirow{2}{*}{ Descrição do fator } & \multicolumn{5}{|c|}{ Frequência de Ocorrência } \\
\hline & & MC & MF & MP & RH & MG \\
\hline 35 & $\begin{array}{l}\text { Disponibilizar compartilhamento de arquivos e documentos aos } \\
\text { usuários (XML, holerites, relatórios e etc.) }\end{array}$ & 01 & 01 & 01 & 01 & 01 \\
\hline 36 & $\begin{array}{l}\text { Ter uma estrutura de hardware satisfatória (rede, servidores, } \\
\text { computadores e etc.) }\end{array}$ & 01 & 01 & 01 & 01 & 01 \\
\hline 37 & Parametrização eficiente e correta & & 02 & 01 & 01 & \\
\hline 38 & Desempenho adequado & & 01 & & 01 & \\
\hline 39 & $\begin{array}{l}\text { Direção da empresa engajada para alterar processos internos devido ao } \\
\text { sistema a fim de atender a legislação }\end{array}$ & & 01 & & & \\
\hline 40 & Conhecimento da empresa que está sendo contabilizada pelo usuário & & 01 & & & \\
\hline 41 & Funcionalidades e tarefas bem definidas & & & & 01 & \\
\hline 42 & Possibilitar um controle adequado de bens & & & 03 & & \\
\hline 43 & Controlar a depreciação fisscal e societária & & & 04 & & \\
\hline 44 & Disponibilidade de conexão com controle de ponto dos funcionários & & & & 03 & \\
\hline 45 & Disponibilização de rotinas completas para controle do $\mathrm{RH}$ & & & & 02 & \\
\hline 46 & Dispõe apenas de funcionalidades e informações necessárias & & & & 02 & \\
\hline 47 & Possibilitar o acesso a várias informações ao mesmo tempo & & & & 01 & \\
\hline 48 & $\begin{array}{l}\text { Sistema oferece tarefas, rotinas, cálculos e apurações confiáveis e } \\
\text { corretos }\end{array}$ & & & & 02 & \\
\hline 49 & $\begin{array}{l}\text { Sistema oferece envio de mensagens importantes aos seus usuários } \\
\text { (férias, aviso prévio e etc.) }\end{array}$ & & & & 03 & 01 \\
\hline 50 & $\begin{array}{l}\text { Disponibilidade de conexão com terceiros, como site Caixa, Correios e } \\
\text { etc. }\end{array}$ & & & & 04 & \\
\hline 51 & Disponibilização de ajuda aos usuários pelo sistema & & & & 01 & \\
\hline 52 & Sistema calcula o custo dos serviços prestados & & & & & 01 \\
\hline 53 & Sistema oferece controle financeiro e gerencial ao escritório & & & & & 03 \\
\hline 54 & Sistema facilita a comunicação com o cliente & & & & & 01 \\
\hline 55 & $\begin{array}{l}\text { Mensuração do tempo de funcionários em cada empresa cliente do } \\
\text { escritório de contabilidade }\end{array}$ & & & & & 02 \\
\hline 56 & Oferece controle de protocolo de entregas de documentos & & & & & 02 \\
\hline 57 & Oferece controle de contratos & & & & & 01 \\
\hline 58 & Apuração total dos impostos & & 01 & & & \\
\hline 59 & $\begin{array}{l}\text { Fornece procedimentos que permitam a análise ou conferência dos } \\
\text { dados ou arquivos antes do envio }\end{array}$ & & 04 & & 01 & \\
\hline 60 & Possibilidade de importação de documentos fiscais (notas) & & 04 & & & \\
\hline 61 & $\begin{array}{l}\text { Oferece gestão do departamento pessoal dos clientes dos escritórios } \\
\text { contábeis }\end{array}$ & & & & 01 & \\
\hline & TOTALIZADORES $\rightarrow$ & 36 & 41 & 36 & 39 & 29 \\
\hline
\end{tabular}

Legenda: $\mathrm{MC}=$ Módulo Contábil; $\mathrm{MF}=$ Módulo Fiscal; $\mathrm{MP}=$ Módulo Patrimônio; RH = Módulo Folha de Pagamento; $\mathrm{MG}=$ Módulo Gestor de Escritório Contábil. 
Como se pode observar na tabela 3 tem-se um total de 61 fatores de sucesso, sendo que alguns foram citados para todos os módulos do SIC (como os fatores 01, 02, 03, 04, entre outros). Também se verifica que alguns fatores são especí đcospor módulo, como os de códigos 10, 39, 40 e 41, entre outros. Assim, na análise dos fatores de sucesso, pode-se observar uma tendência a que estes sejam inerentes a todos os módulos do SIC, com exceção dos que indicam características particulares de cada módulo.

$\mathrm{Na}$ sequência, na tabela 4 são relacionados os 48 fatores críticos de insucesso indicados pelos especialistas, dos quais 36 possuem correspondência com os de sucesso (constantes na tabela 3). Já para os que não possuem correspondência com os fatores críticos de sucesso, estes foram marcados como "sem correspondência - SC".

TABELA 4

Fatores críticos de insucesso indicados pelos especialistas por módulo do SIC (Continua)

\begin{tabular}{|c|c|c|c|c|c|c|c|}
\hline \multicolumn{8}{|c|}{ FATORES DE INSUCESSO (FI) } \\
\hline \multirow{2}{*}{\multicolumn{2}{|c|}{ Cód. $\begin{array}{c}\text { Correspondência } \\
\text { com Fatores de } \\
\text { Sucesso (FS) }\end{array}$}} & \multirow[b]{2}{*}{ Descrição do fator } & \multicolumn{5}{|c|}{ Frequência de Ocorrência } \\
\hline & & & MC & MF & MP & RH & MG \\
\hline 01 & 02 & $\begin{array}{l}\text { Falta ou falha de integração com outros } \\
\text { módulos ou sistemas }\end{array}$ & 07 & 05 & 05 & 04 & \\
\hline 02 & 01 & $\begin{array}{l}\text { Falta de relatórios e de possibilidade de } \\
\text { personalizações das saídas }\end{array}$ & 06 & 01 & 03 & 02 & \\
\hline 03 & 19 & Possuir falhas (bugs / erros) & 04 & 04 & 02 & 02 & \\
\hline 04 & 04 & $\begin{array}{l}\text { Complexidade nas rotinas operacionais } \\
\text { (interface) }\end{array}$ & 04 & 01 & 01 & 02 & \\
\hline 05 & 12 & $\begin{array}{l}\text { Falta de rastreabilidade ou acompanhamento } \\
\text { dos lançamentos (auditoria) }\end{array}$ & 03 & 01 & 02 & & \\
\hline 06 & 07 & Suporte ineficiente & 03 & 03 & 03 & 02 & 01 \\
\hline 07 & 13 & Treinamento aos usuários inadequado & 03 & 02 & 02 & 02 & 01 \\
\hline 08 & 21 & $\begin{array}{l}\text { Software que não atende as necessidades dos } \\
\text { usuários }\end{array}$ & 02 & 01 & 03 & & \\
\hline 09 & 14 & $\begin{array}{l}\text { Falta de comprometimento dos usuários com a } \\
\text { implantação do software }\end{array}$ & 02 & 01 & 01 & 02 & 01 \\
\hline 10 & 06 & Não atendimento às exigências legais & 02 & 02 & & 04 & \\
\hline 11 & 46 & $\begin{array}{l}\text { Funcionalidades ou informações } \\
\text { desnecessárias }\end{array}$ & 02 & 01 & 02 & 01 & \\
\hline 12 & 30 & Ausência do planejamento na implantação & 02 & 01 & 02 & 02 & 02 \\
\hline 13 & 31 & Não possuir melhorias, sistema desatualizado & 02 & 04 & 01 & 03 & 01 \\
\hline 14 & $\mathrm{SC}$ & Equipe de desenvolvimento desmotivada & 01 & 01 & 01 & & \\
\hline 15 & 03 & Difícil usabilidade & 01 & 01 & 01 & 01 & \\
\hline 16 & $\mathrm{SC}$ & $\begin{array}{l}\text { Falta de conectividade com banco de dados } \\
\text { diferentes }\end{array}$ & 01 & 01 & 01 & 01 & 01 \\
\hline 17 & 21 & Software não flexível & 01 & & & 01 & \\
\hline 18 & 28 & Demora na correção de bugs & 01 & 02 & 01 & & \\
\hline 19 & $\mathrm{SC}$ & $\begin{array}{l}\text { Resistência às mudanças dos processos } \\
\text { organizacionais }\end{array}$ & 01 & 01 & & & \\
\hline 20 & 17 & $\begin{array}{l}\text { Uso de tecnologias ultrapassadas ou não } \\
\text { validadas }\end{array}$ & 01 & 01 & 01 & & \\
\hline 21 & $\mathrm{SC}$ & Não ser um sistema totalmente web & 01 & 01 & 01 & 01 & 01 \\
\hline 22 & 10 & $\begin{array}{l}\text { Sistema não parametrizável (Plano de contas } \\
\text { "engessado", eventos RH) }\end{array}$ & 01 & & & 01 & \\
\hline 23 & 05 & $\begin{array}{l}\text { Falta de integração com sistemas do governo } \\
\text { (SPED, FCONT, DIPJ, GIAS, Sintegra, } \\
\text { SEFIP, CAGED, E-SOCIAL, RAIS e etc.) }\end{array}$ & 01 & 04 & & 01 & \\
\hline 24 & 18 & Falta de objetividade & 01 & 01 & 01 & & \\
\hline 25 & 09 & Falta de praticabilidade & 01 & 01 & 01 & & \\
\hline 26 & SC & Permitir alterações pelos usuários (retroativas) & 01 & & 01 & & \\
\hline
\end{tabular}

Fonte: dos autores. 
TABELA 4 (Cont.)

\begin{tabular}{|c|c|c|c|c|c|c|c|}
\hline \multicolumn{8}{|c|}{ FATORES DE INSUCESSO (FI) } \\
\hline \multirow{2}{*}{\multicolumn{2}{|c|}{$\begin{array}{c}\text { Correspondência } \\
\text { Cód. } \quad \begin{array}{c}\text { com Fatores de } \\
\text { Sucesso (FS) }\end{array} \\
\end{array}$}} & \multirow[b]{2}{*}{ Descrição do fator } & \multicolumn{5}{|c|}{ Frequência de Ocorrência } \\
\hline & & & MC & MF & MP & RH & MG \\
\hline 27 & 27 & $\begin{array}{l}\text { Falta de conhecimento contábil pela equipe de } \\
\text { implantação }\end{array}$ & 01 & 01 & & 01 & \\
\hline 28 & $\mathrm{SC}$ & Excesso de confiança dos usuários & 01 & 01 & 01 & 01 & 01 \\
\hline 29 & 15 & Falta de conhecimento contábil dos usuários & 01 & 01 & 02 & 02 & 01 \\
\hline 30 & $\mathrm{SC}$ & $\begin{array}{l}\text { Cobrança excessiva da direção da empresa } \\
\text { com as saídas do software }\end{array}$ & 01 & & & & \\
\hline 31 & $\mathrm{SC}$ & $\begin{array}{l}\text { Falta de qualidade da informação recebida pelo } \\
\text { software }\end{array}$ & 01 & & & & \\
\hline 32 & 26 & $\begin{array}{l}\text { Falta de segurança para acesso ao sistema, } \\
\text { visualização das informações e backup dos } \\
\text { dados. }\end{array}$ & 01 & 01 & 01 & 04 & 02 \\
\hline 33 & 08 & $\begin{array}{l}\text { Baixo nível de validações e automatizações } \\
\text { realizadas pelo sistema }\end{array}$ & & 03 & & 01 & 01 \\
\hline 34 & 60 & $\begin{array}{l}\text { Não importação de documentos fiscais de } \\
\text { forma satisfatória (notas) }\end{array}$ & & 01 & 01 & & \\
\hline 35 & 37 & $\begin{array}{l}\text { Sistema mal parametrizado ou com problemas } \\
\text { na parametrização }\end{array}$ & & 04 & 02 & 03 & \\
\hline 36 & 38 & $\begin{array}{l}\text { Demora no tempo de processamento (lentidão } \\
\text { do sistema) }\end{array}$ & & 01 & & 01 & \\
\hline 37 & $\mathrm{SC}$ & $\begin{array}{l}\text { Equipe de desenvolvimento do software não } \\
\text { capacitada }\end{array}$ & & 01 & & & \\
\hline 38 & 42 & $\begin{array}{l}\text { Não possuir controles adequados para os bens } \\
\text { (depreciação, exaustão, imparment) }\end{array}$ & & & 02 & & \\
\hline 39 & $\mathrm{SC}$ & Sistema mal alimentado & & & 01 & & 1 \\
\hline 40 & $\mathrm{SC}$ & Resistências às mudanças dos usuários & & 01 & 01 & & \\
\hline 41 & 42 & $\begin{array}{l}\text { Não possibilitar o controle adequado e } \\
\text { automatizado de bens }\end{array}$ & & & 01 & & \\
\hline 42 & 43 & Não controlar a depreciação físcal e societária & & & 01 & & \\
\hline 43 & 25 & $\begin{array}{l}\text { Falta de qualidade da informação gerada pelo } \\
\text { software }\end{array}$ & & 04 & 01 & & \\
\hline 44 & 48 & Rotinas, cálculos e apurações errados. & & & & 02 & \\
\hline 45 & $\mathrm{SC}$ & Complexidade na parametrização do sistema & & & & 02 & \\
\hline 46 & 52 & $\begin{array}{l}\text { Falta do cálculo dos custos dos serviços } \\
\text { prestados }\end{array}$ & & & & & 01 \\
\hline 47 & 53 & $\begin{array}{l}\text { Falta do controle financeiro e gerencial do } \\
\text { escritório }\end{array}$ & & & & & 01 \\
\hline 48 & 54 & Falta de comunicação com o cliente & & & & & 01 \\
\hline & & TOTALIZADORES $\rightarrow$ & 32 & 34 & 32 & 26 & 15 \\
\hline
\end{tabular}

Legenda: $\mathrm{SC}=$ Sem Fator de Sucesso Correspondente; $\mathrm{MC}=$ Módulo Contábil; $\mathrm{MF}=$ Módulo Fiscal;

MP = Módulo Patrimônio; RH = Módulo Folha de Pagamento; MG = Módulo Gestor de Escritório Contábil .

Fonte: dos autores. 
Similarmente à análise dos fatores de sucesso, observa-se fatores indicados pelos especialistas que são comuns dentre os módulos do SIC. A grande maioria possui correspondentes de sucesso, o que indica que tais fatores de insucesso correspondem ao inverso do fator de sucesso como, por exemplo, o fator de sucesso código 02 ["Integração com os outros módulos ou sistemas (módulos do SIC e sistemas externos, como por exemplo, sistema de gestão das empresas)"], com o fator de insucesso 01 ["Falta ou falha de integração com outros módulos ou sistemas"]. Também se observa que alguns fatores de sucesso são específicos por módulo do SIC, como por exemplo, 30, 31, 37, 38, 41, 42, entre outros, muito embora tais fatores foram pouco lembrados pelos especialistas. Isto sugere uma menor importância dos mesmos para a medição do êxito dos SIC.

\section{Segunda Rodada Método Delphi}

Para a realização da segunda rodada do método Delphi, inicialmente buscou-se agrupar os fatores críticos de sucesso e insucesso indicados pelos especialistas na primeira rodada com os disponíveis na literatura. Com isto, se pretendia requisitar aos especialistas para indicar quais seriam os fatores mais importantes que contribuem para o sucesso e o insucesso dos SIC.

Cabe destacar que, embora se tenha requisitado aos especialistas a indicação de fatores de sucesso e insucesso nas rodadas Delphi, na análise a seguir tais fatores citados são intitulados de variáveis, as quais em conjunto representam os fatores críticos de sucesso e insucesso.

Sequencialmente, foi realizada a análise conjunta das 99 variáveis da literatura com aquelas obtidas com a primeira rodada do método Delphi (109 variáveis no total, sendo 61 de sucesso e 48 de insucesso). Das variáveis de insucesso citadas pelos especialistas, 34 possuem correspondência com as variáveis de sucesso, totalizando assim $75[61+48-34]$ variáveis de sucesso e insucesso indicadas pelos especialistas. Com isso, unindo as variáveis indicadas pelos especialistas na primeira rodada do método Delphi, com as sugeridas pela literatura, e considerando que existem 13 coincidentes (indicadas pelos especialistas e encontradas na literatura), tem-se um total de 161 variáveis críticas.

Com relação à seleção das variáveis, uma observação se faz necessária. No caso do fator crítico "Qualidade dos Dados Recebidos”, optou-se por manter nesta segunda rodada as 11 variáveis propostas por Kahn, Strong e Wang (2002). Esta decisão foi tomada considerando que houve uma adaptação do fator originalmente proposto pela literatura, e ainda, que o modelo de Kahn et al. (2002) propõe a avaliação da qualidade da informação considerando o aspecto de serviço e de produto da informação.

Das variáveis relacionadas ao fator "Qualidade do Sistema" se desconsideraram duas que foram propostas pela literatura. Estas tratavam de fatores de insucesso ["Necessidade de grande esforço mental para utilizar o sistema (3-SIC)" e "Utilização muitas vezes é frustrante (3-SIC)"], e outras duas por se tratarem de características do usuário, e não do sistema ["Auto eficácia (ou autoconfiança do usuário) (XXX) (5)" e "Experiência tecnológica anterior do usuário (XXX) (5)"]. 
A segunda rodada do método Delphi apresentou aos especialistas as 161 variáveis alocadas nos dez fatores críticos originados do levantamento teórico realizado e descrito no item de proposição de um modelo de avaliação de SIC. Optou-se pela escala Likert como forma de medição da importância atribuída pelos especialistas, por ser a mais indicada para instrumentos longos (Silva Júnior \& Costa, 2014). Para facilitar a compreensão do sistema de numeração e propiciar ganho da informação transmitida, optou-se inicialmente pelo formato de escala de dez pontos (Dalmoro \& Vieira, 2013, Silva Júnior \& Costa, 2014), transformandoa depois em escala de onze pontos com a inserção do ponto neutro. Com isto, se permitia ao respondente estar mais à vontade para expressar sua opinião (Dalmoro \& Vieira, 2013).

Considerando que foram selecionados apenas especialistas com curso superior completo e, principalmente, com conhecimento prévio de SIC, optou-se por indicar a obrigatoriedade de resposta do especialista em todas as variáveis indicadas.

As 161 variáveis foram selecionadas e expostas em assertivas separadas por fator crítico. Com isso, para cada fator crítico, requisitou-se aos especialistas que indicassem o nível de importância de cada variável para representação do fator crítico, variando de "0" (não importante), "01" (pouquíssimo importante) a "10" (muitíssimo importante).

Com as 28 respostas recebidas dos especialistas na segunda rodada Delphi, com o objetivo de selecionar as variáveis mais representativas de cada fator crítico do modelo, foram relacionadas as variáveis em ordem de importância de acordo com a visão dos especialistas inquiridos. Foram calculados os três quartis de cada fator crítico, a fim de separar as variáveis com maior importância das que tinham menor importância, considerando os valores acima do $2^{\circ}$ quartil, representando as variáveis mais importantes. Adicionalmente, foram padronizados os valores absolutos de cada variável na escala de 0 (zero) a 10 (dez) para melhor visualização.

Com isso, diante da análise por quartil das 161 variáveis, foram identificadas 74 variáveis mais expressivas (aquelas relacionadas à $3^{\mathrm{a}} \mathrm{e} 4^{\mathrm{a}}$ partes).

\section{Validação das variáveis mais expressivas selecionadas}

Para as 74 variáveis resultantes da análise anterior, buscou-se realizar uma pré-validação das mesmas. Tal procedimento é recomendável conforme relatado por Chaer, Diniz e Ribeiro (2011), que sugerem a realização de um pré-teste com o instrumento a fim de verificar se as assertivas estão corretamente formuladas. Para isso, os autores sugerem a aplicação entre 10 a 20 respondentes.

Assim, dos 15 usuários experientes de SIC que trabalham em EPSC no Estado do Paraná, para os quais foram requisitadas sugestões de melhorias para as 74 variáveis selecionadas, obteve-se o retorno de 12 usuários. Dos retornos obtidos, os principais ajustes realizados foram: (i) melhorias textuais e de conteúdo das questões; e (ii) duas variáveis que representam o fator crítico "Fatores de Insucesso". Devido à dificuldade de estas variáveis serem respondidas pelos usuários de SIC, foram substituídas por outras duas de maior importância do mesmo fator crítico de acordo com os especialistas. 
De acordo com as adequações sugeridas nas assertivas, na tabela 5 é listado o conjunto final das variáveis com suas respectivas origens e fatores preditores relacionados.

TABELA 5

\section{Composição dos constructos e origem das variáveis (Continua)}

\begin{tabular}{|c|c|c|}
\hline Constructo & Descrição das variáveis & Origem \\
\hline \multirow{9}{*}{$\begin{array}{l}\text { Qualidade do } \\
\text { dado recebido }\end{array}$} & Os dados recebidos pelo SIC são verdadeiros e confiáveis [credibilidade] & Literatura \\
\hline & Os dados recebidos pelo SIC são úteis [utilidade] & Literatura \\
\hline & Os dados recebidos pelo SIC são compreensíveis [entendimento] & Literatura \\
\hline & Os dados recebidos pelo SIC são corretos e confiáveis [livre de erros] & Literatura \\
\hline & Os dados recebidos pelo SIC são aplicáveis e úteis [relevância] & Literatura \\
\hline & Os dados recebidos pelo SIC atendem minhas necessidades & Literatura \\
\hline & $\begin{array}{l}\text { Tenho disponível os dados que são recebidos pelo SIC de forma integrada } \\
\text { [integração] }\end{array}$ & Literatura \\
\hline & $\begin{array}{l}\text { Os dados recebidos pelo SIC são suficientemente atualizados para o trabalho } \\
\text { [atualidade] }\end{array}$ & Literatura \\
\hline & $\begin{array}{l}\text { Os dados recebidos pelo SIC são claros e apresentam linguagem, unidades de } \\
\text { medida e símbolos apropriados }\end{array}$ & Literatura \\
\hline \multirow{5}{*}{$\begin{array}{l}\text { Qualidade do } \\
\text { serviço }\end{array}$} & A equipe de desenvolvimento do SIC que utilizo é capacitada & Especialistas \\
\hline & A equipe de implantação do SIC que utilizo é capacitada & Especialistas \\
\hline & O SIC teve parametrização eficiente e correta & Especialistas \\
\hline & O suporte técnico do SIC é eficiente e acessivel & Especialistas \\
\hline & $\begin{array}{l}\text { Existe comprometimento da empresa desenvolvedora do SIC com sua } \\
\text { implantação }\end{array}$ & Especialistas \\
\hline \multirow{7}{*}{$\begin{array}{l}\text { Características } \\
\text { da tarefa }\end{array}$} & O SIC oferece rotinas, cálculos e apurações confiáveis e corretos. & Especialistas \\
\hline & O SIC faz a apuração total dos impostos & Especialistas \\
\hline & O SIC controla a depreciação fiscal e societária & Especialistas \\
\hline & $\begin{array}{l}\text { O SIC tem rotinas automatizadas (alteração em massa de lançamentos, } \\
\text { encerramento de exercícios, cálculos de folha, apuração de tributos, etc.) }\end{array}$ & Especialistas \\
\hline & O SIC tem funcionalidades bem definidas & Ambos \\
\hline & O SIC disponibiliza rotinas completas para controle do RH & Especialistas \\
\hline & O SIC possibilita um controle adequado de bens & Especialistas \\
\hline \multirow{17}{*}{$\begin{array}{l}\text { Qualidade do } \\
\text { sistema }\end{array}$} & O SIC atende as exigências da legislação vigente, tanto fiscal como trabalhista. & Especialistas \\
\hline & O SIC, seus relatórios e processos são confiáveis & Ambos \\
\hline & O SIC possibilita a importação de documentos físcais (notas) & Especialistas \\
\hline & $\begin{array}{l}\text { O SIC é integrado e tem integração com os outros módulos ou sistemas (entre } \\
\text { os módulos do SIC e sistemas externos) }\end{array}$ & Ambos \\
\hline & O SIC garante a veracidade dos resultados & Literatura \\
\hline & $\begin{array}{l}\text { O SIC é capaz de gerar as obrigações acessórias exigidas pelo governo [fisco] } \\
\text { (SPED Fiscal, EFD-Contribuições, ECD, ECF, SEFIP, GEFIP, CAGED, etc.) }\end{array}$ & Especialistas \\
\hline & O SIC tem segurança dos dados e informações & Especialistas \\
\hline & O SIC é atualizado & Especialistas \\
\hline & O SIC é fácil de usar & Ambos \\
\hline & $\begin{array}{l}\text { O SIC é consolidado as regras do negócio para controlar as operações das } \\
\text { empresas contabilizadas }\end{array}$ & Especialistas \\
\hline & O SIC possibilita facilidade de aprendizagem para seu uso & Ambos \\
\hline & O SIC é melhorado de forma contínua & Especialistas \\
\hline & O SIC é objetivo & Especialistas \\
\hline & O SIC tem controle de acesso aos usuários & Especialistas \\
\hline & O SIC é bem desenvolvido & Especialistas \\
\hline & O SIC é ágil & Ambos \\
\hline & O SIC é livre de erros (bugs) & Especialistas \\
\hline
\end{tabular}


TABELA 5 (Cont.)

\begin{tabular}{|c|c|c|}
\hline Constructo & Descrição das variáveis & Origem \\
\hline \multirow{4}{*}{ Aspectos sociais } & Eu possuo domínio do SIC & Literatura \\
\hline & Eu tenho conhecimento contábil e de legislação & Especialistas \\
\hline & Eu conheço a(s) empresa(s) que está(ão) sendo contabilizada(s) por mim & Especialistas \\
\hline & Eu avalio que tenho resultados positivos com o uso do SIC & Literatura \\
\hline \multirow{5}{*}{$\begin{array}{c}\text { Aspectos } \\
\text { organizacionais }\end{array}$} & $\begin{array}{l}\text { Eu tenho comprometimento por vontade própria com a organização que } \\
\text { trabalho [compromisso afetivo] }\end{array}$ & Literatura \\
\hline & $\begin{array}{l}\text { A direção da empresa em que trabalho é comprometida em ajustar processos } \\
\text { internos requisitados pelo SIC, a fim de atender a legislação } \\
\end{array}$ & Especialistas \\
\hline & Os usuários do SIC da empresa em que trabalho são orientados ao resultado & Literatura \\
\hline & Os usuários do SIC da empresa em que trabalho são atentos aos detalhes & Literatura \\
\hline & Os usuários do SIC da empresa em que trabalho possuem orientação a equipe & Literatura \\
\hline \multirow{5}{*}{$\begin{array}{l}\text { Fatores de } \\
\text { insucesso }\end{array}$} & A empresa em que trabalho tem resistência às mudanças em seus processos & Especialistas \\
\hline & Falta qualidade na informação recebida pelo SIC & Especialistas \\
\hline & Complexidade na parametrização do SIC & Especialistas \\
\hline & $\begin{array}{l}\text { Os usuários do SIC da empresa em que trabalho apresentam resistência às } \\
\text { mudanças }\end{array}$ & Especialistas \\
\hline & O SIC é mal alimentado & Especialistas \\
\hline \multirow{6}{*}{ Uso } & Eu utilizo de forma adequada o SIC & Literatura \\
\hline & Eu utilizo o SIC para a finalidade pretendida & Literatura \\
\hline & Eu utilizo o SIC com propósito adequado & Literatura \\
\hline & O SIC é adequado para seu uso & Literatura \\
\hline & Eu utilizo o SIC com informação apropriada & Literatura \\
\hline & Eu utilizo o SIC em uma intensidade de uso apropriada & Literatura \\
\hline \multirow{3}{*}{$\begin{array}{l}\text { Satisfação do } \\
\text { usuário }\end{array}$} & O SIC é eficiente, ou seja, o sistema faz o que precisa ser feito & Literatura \\
\hline & O SIC tem eficácia, ou seja, o uso do sistema traz bons resultados & Literatura \\
\hline & Eu tenho satisfação geral com o SIC & Literatura \\
\hline \multirow{13}{*}{$\begin{array}{l}\text { Benefícios } \\
\text { líquidos }\end{array}$} & O SIC aumenta a produtividade geral da organização & Literatura \\
\hline & O SIC melhora a qualidade dos serviços fiscais & Literatura \\
\hline & O SIC simplifica e padroniza o processo de tributação & Literatura \\
\hline & O SIC moderniza o processo de tributação & Literatura \\
\hline & O SIC reduz o prazo de entrega das obrigações tributárias & Literatura \\
\hline & No geral, o SIC é útil para o meu trabalho & Literatura \\
\hline & O SIC é um elemento essencial no processo de tributação & Literatura \\
\hline & O SIC permite realizar minhas tarefas mais rapidamente & Literatura \\
\hline & A informação contábil gerada pelo SIC tem precisão & Literatura \\
\hline & A informação contábil gerada pelo SIC é de qualidade & Especialistas \\
\hline & A informação contábil gerada pelo SIC tem relevância & Literatura \\
\hline & A informação contábil gerada pelo SIC é atual & Literatura \\
\hline & A informação contábil gerada pelo SIC é completa & Literatura \\
\hline
\end{tabular}

Fonte: dos autores 
$\mathrm{Na}$ Figura 1 é exposto o modelo indicando o nmero de variáveis representativas para cada fator crítico, considerando os 10 fatores do modelo proposto, as 74 variáveis selecionadas, bem como a relação entre os fatores verificada no levantamento teórico realizado.

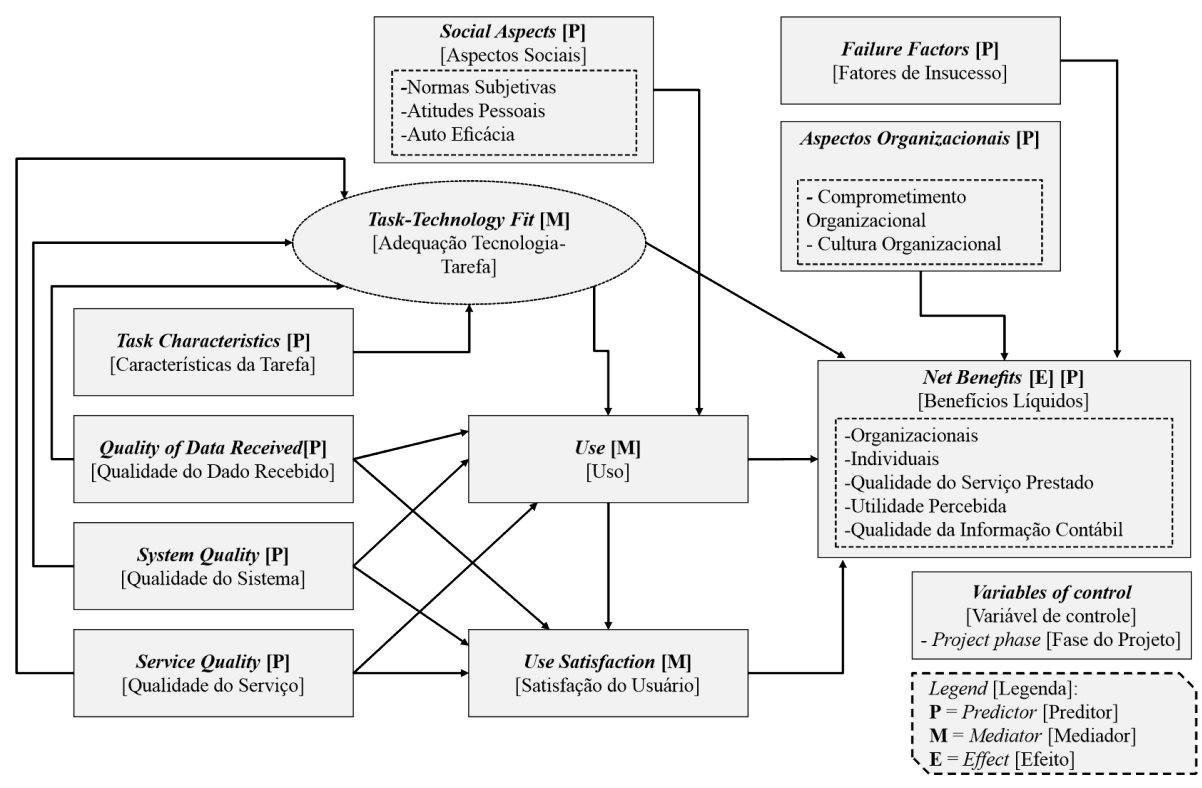

FIGURA 1

Modelo teórico proposto

Fonte: os autores.

Em resumo, a partir do levantamento teórico realizado, o modelo para avaliação do sucesso do SIC nas EPSC propõe que a "Adequação Tecnologia-Tarefa" (TTF) representada pelos fatores críticos de "Qualidade do Serviço", "Qualidade do Sistema”, "Qualidade do Dado Recebido" e "Características da Tarefa”, podem influenciar o "Uso" e a "Satisfação do Usuário". Estes úúltimos, por sua vez, juntamente com o fator "TTF” poderão influenciar os "Benefícios Líquidos" gerados pelo SIC. O modelo teórico evidencia ainda que os "Aspectos Sociais" podem influenciar o "Uso" do SIC, bem como os "Aspectos Organizacionais" e os "Fatores de Insucesso" podem influenciar os "Benefícios Líquidos". Por fim, destaca-se o "Fase de Projeto" como uma variável de controle de modelo proposto.

Finalmente, é importante destacar que as 74 variáveis selecionadas, representadas pelos dez fatores críticos do modelo possuem a seguinte origem: $31(41,9 \%)$ foram sugeridas pelos especialistas, 37 (50,0\%) pela literatura pesquisada e $6(8,1 \%)$ por ambos. Tais percentuais reforçam a contribuição das variáveis sugeridas pelos especialistas na primeira rodada do Método Delphi, pois 41,9\% das variáveis selecionadas não advém da literatura pesquisada. Ainda, pelos ajustes realizados na validação das variáveis, observou-se que estes foram importantes para futura aplicação e validação em campo, deixando as questões mais claras e completas para o entendimento dos respondentes.

\section{Considerações finais}

Este estudo teve por objetivo a proposição de um modelo composto de fatores críticos que in Átenciam no sucesso dos SIC nas EPSC brasileiras.

Para o alcance de tal objetivo, primeiramente buscou-se mapear e selecionar os fatores críticos e suas respectivas variáveis que possibilitam avaliar o êxito dos SIC. Com este intuito, foram selecionados os fatores críticos por meio de uma vasta revisão na literatura dos vários modelos existentes de avaliação de sistemas de informações em geral, bem como dos específicos de SIC. A partir destes fatores se construiu o modelo proposto na Figura 1. 
A partir dos fatores críticos selecionados, foi realizada a primeira rodada do método Delphi com a participação de 30 especialistas, que sugeriram 75 variáveis críticas de sucesso e insucesso, as quais posteriormente foram reunidas com as indicadas pela literatura [99] que, ao retirar as coincidentes, totalizaram 161. Finalmente, foi necessário selecionar as variáveis mais expressivas para representarem os fatores críticos utilizados para avaliação do êxito dos SIC. Para isso, foi realizada uma segunda rodada do método Delphi na qual foi requisitado aos especialistas indicarem as variáveis mais importantes para representação dos dez fatores críticos do modelo teórico proposto. Assim, foram obtidas as 74 variáveis mais expressivas na visão dos especialistas para representação dos fatores críticos, as quais passaram por uma etapa de validação com 12 usuários de SIC.

Perante os procedimentos descritos, entende-se que o objetivo geral desta pesquisa foi alcançado, pela disponibilização de um modelo teórico que avalia os fatores críticos que influenciam no êxito dos SIC nas EPSC brasileiras. Assim, com os resultados alcançados, alguns detalhamentos e contribuições são observados a seguir.

As contribuições do estudo relacionam-se à constatação de algumas particularidades dos SIC que futuras pesquisas devem levar em consideração. Isto acrescenta a necessidade de um modelo específico para tais sistemas. Estas particularidades são elencadas a seguir: (i) uso obrigatório; (ii) procedimentos e tarefas essencialmente padronizados a fim de atender normas e legislações governamentais, diferentemente de outros sistemas em que suas tarefas são adequadas de acordo com as necessidades da organização, como um ERP por exemplo; (iii) aptidão no recebimento de vários arquivos de dados oriundos de diversos sistemas, os quais devem ser importados e processados de forma mais correta possível; (iv) aptidão de geração de variados arquivos, essencialmente governamentais [obrigações acessórias], no formato e periodicidade exigidos pela legislação; (v) sistema voltado especialmente para atender as necessidades fiscais, contábeis e de folha de pagamento dos clientes da EPSC, e não do próprio escritório contábil utilizador do SIC; e (vi) software atualizado tempestivamente de acordo com as exigências legais.

Além disso, observou-se a lacuna na literatura de variáveis representativas dos fatores "Qualidade do Serviço" e "Qualidade da Informação", como constatado por Petter et al. (2013). Sendo assim, a pesquisa contribui para reduzir a referida lacuna, por: (i) ter encontrado variáveis para representação da qualidade do serviço; (ii) ter indicado variáveis que avaliam a qualidade das informações recebidas, nesta pesquisa representada pelo constructo teórico "Qualidade do Dado Recebido"; e (iii) apresentar variáveis a fim de avaliar a qualidade da informação gerada, no caso desta pesquisa representada por assertivas do fator "Benefícios Líquidos", subgrupo "Qualidade da Informação Contábil”.

Destarte, considerando os resultados encontrados, indicam-se para pesquisas futuras: (i) teste e validação do modelo proposto na realidade dos SIC das EPSC brasileiras; (ii) utilização da metodologia proposta na concepção do instrumento de coleta de dados para outros tipos de sistemas de informações; (iii) replicação do modelo em outros países a fim de avaliar as semelhanças e diferenças entre os fatores críticos, contribuindo ao melhor entendimento dos fatores e suas respectivas causas e efeitos.

Por fim, entende-se que o modelo proposto é limitado aos SIC utilizados por EPSC brasileiras, de modo que, para EPSC de outros países, ou ainda, aos SIC não utilizados por escritórios contábeis, o emprego do modelo e suas variáveis deve ser realizado com cautela.

\section{Considerações éticas}

A pesquisa não exigiu endosso ético dos participantes. 


\section{Contribuição dos autores}

O autor Ricardo A. Antonelli contribui desde o levantamento do portfólio bibliográfico, aplicação dos questionários, análise dos resultados e conclusão da pesquisa. A autora Simone Bernardes Voese orientou toda a pesquisa, sugerindo os direcionamentos necessários e realizando correçóes no decorrer na pesquisa. O autor Gilson Ditzel Santos coorientou a pesquisa, contribuindo especialmente na formulação do modelo teórico proposto, bem como no refinamento dos resultados alcançados. A autora Marivânia Rufato da Silva sintetizou toda estrutura da pesquisa, trazendo novas referências e ajustando toda parte textual e de formatação para a revista.

\section{Conflitos de interesse}

Não há nenhum conflito de interesse dos autores com qualquer aspecto da presente pesquisa.

\section{Agradecimentos}

A presente pesquisa não recebeu nenhum financiamento para elaboração e submissão do artigo.

\section{Referências}

Al-Debei, M. M., Jalal, D., \& Al-Lozi, E. (2013). Measuring web portals success: A resecification and validation of the DeLone and McLean information systems success model. International Journal of Business Information Systems (vol. 14). http://doi.org/10.1504/IJBIS.2013.055555

Bugarim, M. C. C. (2012). desenvolvimento e gestão de programas de capacitação mediados por tecnologia: proposição de um arcabouço terico nombito da governança corporativa. Florianpolis: Universidade Federal de Santa Catarina.

Capozoli, R. (2014). Contadores passam por consolidação. Retrieved from http://www.portalcfc.org.br/noticia.php?n $\mathrm{ew}=12875$

CFC. (2017). Profisionais Ativos nos Conselhos Regionais de Contabilidade. Retrieved November 3, 2017, from ht tp://www3.cfc.org.br/spw/crcs/ConselhoRegionalAtivo.aspx

Chaer, G., Diniz, R. R. P., \& Ribeiro, E. A. (2011). A ténica do questionário na pesquisa educacional. Revista Evidencia, 7 (7), 251-266. http://www.uniaraxa.edu.br/ojs/index.php/evidencia/article/view/201

Coelho, R. D. P., \& Souza, A. A. de. (2005). Sistema de informações contábeis e satisfação das necessidades informacionais dos usuários. II Simpósio de Excelência Em Gestão e Tecnologia - SEGeT, pp. 458-472. Resende - RJ.

Cooper, D. R., \& Schindler, P. S. (2003). Métodos de pesquisa em administração, 7th ed. Porto Alegre: Bookman.

Correa, P. R., Peréz, J. A., \& Flores, L. C. (2016). Meta analysis of the DeLone and McLean information systems success model at individual level\#e an examination of the heterogeneity of the studies. Revista Espacios, 36(13), 1-13. h ttp://www.revistaespacios.com/a15v36n13/15361311.html

Dalmoro, M., \& Vieira, K. M. (2013). Dilemas na construção de escalas tipo Likert: o número de itens e a disposição influenciam nos resultados? Revista Gestão Organizacional, 6 (ES), 161-174. https://bell.unochapeco.edu.br/ revistas/index.php/rgo/article/viewFile/1386/1184

Davis, F. D. (1986). A technology acceptance model for empirically testing new end-user information systems: Theory and results. Cambridge: Massachusetts Institute of Technology.

Davis, F. D., Bagazzi, R. P., \& Warshaw, P. R. (1989). User Acceptance of Computer Technology: a Comparison of Two Theoretical Models. Management Science, 35(8), 982-1003. http://doi.org/10.1287/mnsc.35.8.982 
DeLone, W. H., \& McLean, E. (1992). Information systems success: The quest for the dependent variable. Information Systems Research, 3(1). https://doi.org/10.1287/isre.3.1.60

DeLone, W. H., \& McLean, E. (2003). DeLone and McLean model of information systems success: A ten-year update. Journal of Management Information Systems, 19(4), 9-30. https://www.tandfonline.com/doi/ abs/10.1080/07421222.2003.11045748

Dwivedi, Y. K., Wastell, D., Laumer, S., Henriksen, H. Z., Myers, M. D., Bunker, D. Srivastava, S. C. (2015). on information systems failures and successes: Status update and future directions. Information Systems

Frontiers, 17(1), 143-157. http://doi.org/10.1007/s10796-014-9500-y

Esteves, J. G. C. (2007). O sucesso dos Sistemas de Informação. Lisboa: Universidade Técnica de Lisboa.

Etim, E. O. (2011). Enhancing the efficiency of Accounting Information System in Organizations. International Journal of Economic Development Research and Investment, 2(2), 19-27. http://www.icidr.org/doc/ICIDR\%20 PDF\%20contents/international\%20journal\%20of\%20eco.dev.res.invt/enhancing\%20the\%20efficiency.pdf

Fitriati, A., \& Mulyani, S. (2015). Factors that affect accounting information system success and its implication on accounting information quality. Asian Journal of Information Technology, 14(5), 154-161. http://dx.doi.org/1 $0.36478 /$ ajit.2015.154.161

Floropoulos, J., Spathis, C., Halvatzis, D., \& Tsipouridou, M. (2010). Measuring the success of the Greek Taxation Information System. International Journal of Information Management, 30(1), 47-56. http://doi.org/10.1016/ j.ijinfomgt.2009.03.013

Fowler, J., \& Horan, P. (2008). Evolutionary Concepts in End User Productivity and Performance: Applications for Organizational Progress. In S. Clarke (ed.), Information Science Reference. Hershey, New York: Information Science Reference. http://doi.org/10.1017/CBO9781107415324.004

Freitas, L. C. (2013). Modelo de fatores de sucesso para avaliação de softwares educacionais aplicados ao ensino de ciências. Universidade Federal de Itajubá.

Gable, G. G., Sedera, D., \& Chan, T. (2003). Enterprise systems success: A measurement model. In International Conference on Information Systems (pp. 576-591). http://doi.org/doi=10.1.1.95.2176\&rep=rep1\&type=pdf

Giovinazzo, R. A. (2001). Modelo de aplicação da metodologia Delphi pela Internet - vantagens e ressalvas. Administração On Line, 2(2), 1-7. http://www.fecap.br/adm_online/art22/renata.htm

Goodhue, D. L., \& Thompson, R. L. (1995). Task-technology Ætand individual performance. MIS Quarterly, 19(2), 213-236. https://doi.org/10.2307/249689

Gray, G. L., Chiu, V., Liu, Q., \& Li, P. (2014). Ae expert systems life cycle in AIS research: What does it mean for future AIS research? International Journal of Accounting Information Systems, 15(4), 423-451. http://doi.org/ 10.1016/j.accinf.2014.06.001

Grisham, T. (2009). The Delphi technique: A method for testing complex and multifaceted topics. International Journal of Managing Projects in Business, 2(1), 112-130. http://doi.org/10.1108/17538370910930545

IBGE. (2014). Instituto Brasileiro de Geografia Estatística. Retrieved December 12, 2014, from https://www.ibge .gov.br/

Ifinedo, P. (2006). Extending the Gable et al. enterprise systems success measurement model: A preliminary study. Journal of Information Technology Management, XVII(1), 14-33. http://doi.org/10.1108/09556220910959990

Kahn, B. K., Strong, D. M., \& Wang, R. Y. (2002). Information quality benchmarks: product and service performance. Communications of the ACM, 45(4), 184-192. http://doi.org/10.1145/505999.506007

Lopes, A. C. T. (2011). Sistemas de informação em escritórios Brasileiros de assessoria contábil para micro e pequenas empresas: um estudo sob a ótica Neopatrimonialista. Revista Mineira de Contabilidade, 12(41), 13-21. https:// revista.crcmg.org.br/rmc/article/download/323/142

Machado, C. P., \& Oliveira, V. (2006, October). Sistemas integrados de gestão: efetividade e evolução. Encontro Nacional de Engenharia de Produção, pp. 1-9.

Markus, M. L., \& Tanis, C. (2000). Ae Enterprise System Experience - from adoption to success. In R. Zmud (ed.), Framing the domains of IT Management: Projecting the future through the past (Pinnaflex pp. 173-207). Cincinnatti. http://doi.org/10.1145/332051.332068 
Moura, I. C. A. A. (1997). Avaliação de sucesso de sistemas de apoio ao trabalho de grupo - algumas questões. Universidade do Minho.

Mulyani, S., Hassan, R., \& Anugrah, F. (2016). The critical success factors for the use of information systems and its impact on the organizational performance. International Business Management, 10(4), 552-560. http:// dx.doi. org/10.36478/ibm.2016.552.560

Nelson, R. R. (2005). Project retrospectives: Evaluating project success, failure, and everything in between. MIS Quarterly Executive, 4(3), 361-372. Retrieved from http://www2.commerce.virginia.edu/cmit/Research/MIS QE9-05.pdf

Nelson, R. R. (2007). IT project management: infamous failures, classic mistakes, and best practices. MIS Quarterly Executive, 6(2), 67-78. https://www.academia.edu/download/37052381/IT_Project_Management.pdf

Petter, S., DeLone, W., \& McLean, E. R. (2013). Information systems success: The quest for the independent variables. Journal of Management Information Systems, 29(4), 7-62. http://doi.org/10.2753/MIS0742-1222290401

Rosemman M., \& Wiese, J. (1999). Measuring the Performance of ERP Software. In 10th Australasian Conference on Information Systems (pp. 773-784).

Sabherwal, R., Jeyaraj, A., \& Chowa, C. (2006). Information System Success: Individual and organizational determinants. Management Science, 52(12), 1849-1864. http://doi.org/10.1287/mnsc.1060.0583

Sanchez, O. P., Cruz, M. A., \& Agapito, P. R. (2012, September). Investigação sobre o Sucesso de Sistemas para Ensino a Distância no Brasil: uma abordagem com Partial Least Square. XXXVI EnANPAD, pp. 1-16. Rio de Janeiro.

Santos, A. M., Beltrame, M., \& Lunardi, G. (2007). Validação de um instrumento para avaliar o sucesso de sistemas de gestão do conhecimento. IV Simpósio de Excelência Em Gestão e Tecnologia, pp. 1-15. Resende - RJ.

Seddon, P. B. (1997). A respecification and extension of the DeLone and McLean model of IS Success. Information Systems Research, 8(3), 240-253. https://doi.org/10.1287/isre.8.3.240

Seddon, P., \& Kiew, M.-Y. (1996). A Partial Test and Development of Delone and Mclean's Model of IS Success. Australasian Journal of Information Systems, 4(1), 90-109. http://doi.org/10.3127/ajis.v4i1.379

SESCON-SP. (2014). Pesquisa de preços e serviços praticados pelas organizações contábeis do Estado de São Paulo. SESCON-SP / AESCON-SP.

Silva Júnior, S. D., \& Costa, F. J. (2014). Mensuração e Escalas de Verificação: uma Análise Comparativa das Escalas de Likert e Phrase Completion. PMKT - Revista Brasileira de Pesquisa de Marketing, Opinião e Mídia, 15, 116. http://www.revistapmkt.com.br

Smyth, R. W. (2001). Challenges To Successful Erp Use - Research in Progress. In the 9th European Conference on Information Systems (pp. 1227-1231). Slovenia.

Souza, A. A. de, \& Passolongo, C. (2005). Avaliação de Sistemas de Informações Financeiras: estudo de casos múltiplos. UnB Contábil, 8(2), 177-205. https://www.revistacgg.org/contabil/article/view/165/pdf_88

Stefanou, C. (2001). A framework for the ex-ante evaluation of ERP software. European Journal of Information Systems, 10(10), 204-215. http://doi.org/10.1057/palgrave.ejis.3000407

Sun, J., \& Teng, J. T. C. (2012). Information Systems Use: Construct conceptualization and scale development. Computers in Human Behavior, 28(5), 1564-1574. http://doi.org/10.1016/j.chb.2012.03.016

Susanto, A. (2015). What factors influnce the quality of Accounting Information? IJABER, 13(6), 3995-4014. http s://www.academia.edu/download/52507587/1457760294.pdf

Wixom, B. H., \& Todd, P. A. (2005). A theoretical integration of user satisfaction and technology acceptance. Information Systems Research, 16(1), 85-102. http://doi.org/10.1287/isre.1050.0042

Wright, J. T. C., \& Giovinazzo, R. A. (2000). Delphi: uma ferramenta de apoio ao planejamento prospectivo. Caderno de Pesquisas em Administraçao, 1(12), 54-65. http://www.fundacaofia.com.br/profuturo/Uploads/Document s/Artigos/art50.htm

Wu, J. H., \& Wang, Y. M. (2006). Measuring KMS success: A respeciÆation of the DeLone and McLean's model. Information and Management, 43(6), 728-739. http://doi.org/10.1016/j.im.2006.05.002 
Ricardo Adriano Antonelli, et ai. Sistemas de informações contábeis: proposição de um modelo...

Zwirtes, A., \& Alves, T. W. (2014). Os impactos causados pela inovação tecnológica em escritórios de contabilidade do Rio Grande Do Sul: uma análise fatorial. Revista de Educação e Pesquisa em Contabilidade (REPeC), (1), 39-53. http://doi.org/10.17524/repec.v8i1.936

\section{Notas}

* $\quad$ Artigo de Pesquisa Científica e Tecnológica.

Licencia Creative Commons CC BY 4.0

Para citar este artigo: Antonelli, R. A., Voese, S. B., Santos, G. D., \& Silva, M. R. (2021). Sistemas de informações contábeis: proposição de um modelo de avaliação dos fatores críticos de sucesso. Cuadernos de Contabilidad, 22. https://doi.org/10.11144/Javeriana.cc22.sicp 